\title{
Optimalisasi Pendistribusian Susu Nasional dengan Menggunakan Metode Assignment (Hungarian) dan Metode Networking Spanning Tree
}

\author{
Indah Purnama Sari ${ }^{1 *}$, Rianita Puspa Sari ${ }^{2}$, Wahyudin ${ }^{3}$, Ida Rinjani ${ }^{4}$ \\ 1,2,3,4 Industrial Engineering Department, Universitas Singaperbangsa Karawang \\ *Koresponden email: indahpurnamasari890@ gmail.com
}

Diterima: 31 Juli 2021

Disetujui: 10 Agustus 2021

\begin{abstract}
The problems at the National Dairy Depot are sales productivity problems, with regard to the assignment of workers, as well as the distribution network in Teluk Jambe Timur District, which comprises nine employees. The goal of this research is to optimize distance and time in distributing National Milk. The method used for the assignment of workers is the Assignment method (Hungarian) and to optimize the allocation of milk by the distribution system using the Networking method (Spanning Tree). As a result of these two methods, the optimal allocation of products sold is 1350 pieces of national milk, and the minimum distance to be traveled by workers in distribution of national milk is $39.18 \mathrm{Km}$.
\end{abstract}

Keywords: Hungarian, assignment, networking, spanning tree, distribution, milk

\begin{abstract}
Abstrak
Permasalahan pada depot susu Nasional yaitu masalah produktivitas penjualan, mengenai penugasan pekerja, serta mengenai jaringan alokasi distribusi di Kecamatan Teluk Jambe Timur yang berjumlah sembilan orang pekerja, Tujuan dari penelitian ini adalah untuk mengoptimalkan jarak serta waktu dalam pendistribusian Susu Nasional. Metode yang digunakan dalam penugasan pekerja yaitu dengan metode Assignment (Hungarian), serta untuk mengoptimalkan jaringan alokasi distribusi susu tersebut dengan menggunakan metode Networking (Spanning Tree). Penggunaan kedua metode tersebut didapat alokasi total produk yang terjual optimumnya berjumlah 1350 buah susu nasional, serta besarnya jarak minimum yang harus ditempuh oleh pekerja dalam mendistribusikan susu nasional adalah sebesar 39,18 Km.
\end{abstract}

Kata Kunci: Hungarian, assignment, networking, spanning tree, distribusi, susu

\section{Pendahuluan}

CV. Citra Nasional yang berlokasi di Semarang Jawa Tengah, merupakan perusahaan yang bergerak dibidang pengolahan susu, pasteurisasi dan yoghurt. Perusahaan tersebut berdiri sejak tahun 2000, dan sampai kini perusahaan tersebut masih exis dengan produk susu yang cukup familiar di kalangan masyarakat seperti susu NASIONAL dan yoghurt NASIONAL. Bahkan hingga sekarang CV. Citra Nasional sudah memiliki beberapa depot yang tersebar hampir semua tempat di pulau Jawa, termasuk yang ada di wilayah Kecamatan Teluk Jambe Timur Kabupaten Karawang.

Dalam penelitian ini pemilihan Depot Susu Nasional yang berada di Kabupaten Kawarang, menjadi objek penelitian dan sebagai sumber data primer yang digunakan untuk dianalisa permasalahan sekaligus mencari solusi yang terbaik dari permasalahan tersebut. Depot Susu Nasional Kecamatan Teluk Jambe Timur ini, memiliki 9 karyawan yang bertugas untuk menjajakan produk-produk susu tersebut di sekitar wilayah Kecamatan Teluk Jambe Timur, dengan jam kerja dimulai pukul 09.00-18.00 WIB.

Permasalahan tersebut seperti pada bagian penugasan setiap karyawan dalam menjajakan produknya. Lalu juga mengenai ketidaktahuan karyawan tentang rute (wilayah) mana saja yang harus mereka jajaki agar penjualan produk susu tersebut optimal dengan waktu yang efisien, sehingga dihasilkan keuntungan yang maksimal. Maka dari itu dengan adanya permasalahan tersebut menjadi salah satu masalah yang dapat dipecahkan dengan metode Riset Operasi, yaitu metode Penugasan (Assignment / Hungarian) dan metode Networking

Tujuan dari penelitian ini adalah untuk mengetahui bagaimana agar penugasan setiap karyawan Depot Susu Nasional dengan setiap pekerjaan mereka lakukan dapat menghasilkan solusi optimal, mengetahui berapa banyak jumlah produk susu nasional yang harus dialokasikan pada setiap karyawannya, 
untuk mengetahui bagaimana cara menentukan rute penjualan Susu Nasional di sekitar Kecamatan Teluk Jambe Timur, dan untuk mengetahui berapa jarak minimum yang bisa ditempuh setiap pekerja guna meminimalisir biaya namun menghasilkan keuntungan yang optimal.

Metode Hungarian merupakan metode modifikasi baris dan kolom pada matriks efektivitas hingga muncul komponen nol tunggal dalam setiap baris atau kolom yang dipilih sebagai lokasi penugasan [1]. Syarat pada metode Hungarian adalah jumlah harus sama, setiap sumber mengerjakan satu tugas, jika jumlah tugas tidak sama dengan jumlah sumber maka diperlukannya penambahan variabel dummy worker dan dummy job. Adapun permasalahan yang dapat diselesaikan dengan metode Hungarian adalah meminimumkan kerugian seperti biaya, waktu, jarak dan sebagainya [2].

Metode Hungarian digunakan untuk mengurangi biaya produksi serta meminimumkan waktu sehingga dapat diterapkan oleh perusahaan dalam meningkatkan produksi [3] penugasan berkaitan dengan masalah penetapan tugas dari seorang pekerja atau suatu objek dengan tujuan tertentu [4]. Networking merupakan suatu himpunan titik-titik, yang disebut simpul atau node, serta suatu himpunan kurva yang disebut cabang atau busur, yang menghubungkan titik pada sampul tertentu [5]. Spanning Tree merupakan metode dari Analisa jaringan dalam menentukan busur yang menghubungkan antar node yang memberikan rentang busur minimal [6].

\section{Metode Penelitian}

Metode penelitian merupakan cara yang digunakan atau diperlukan untuk penelitian secara matematis dalam Menyusun sebuah penelitian untuk memecahkan suatu masalah [7]. Tujuan dari penelitian ini adalah untuk mengetahui bagaimana agar penugasan setiap karyawan Depot Susu Nasional dengan setiap pekerjaan mereka lakukan dapat menghasilkan solusi optimal, mengetahui berapa banyak jumlah produk susu nasional yang harus dialokasikan pada setiap karyawannya, untuk mengetahui bagaimana cara menentukan rute penjualan Susu Nasional di sekitar Kecamatan Teluk Jambe Timur, dan untuk mengetahui berapa jarak minimum yang bisa ditempuh setiap pekerja guna meminimalisir biaya namun menghasilkan keuntungan yang optimal.

Identifikasi Masalah

Mengidentifikasi masalah pada studi kasus bertujuan untuk mengetahui permasalahan yang terjadi pada tempat yang diteliti dengan melakukan observasi dan wawancara secara langsung, adapun permasalahan yang terjadi adalah mengenai penugasan pekerja di Depot Susu Nasional di Kecamatan Teluk Jambe Timur yang berjumlah sembilan orang pekerja, dengan tugas mendistribusikan produk susu ke desadesa yang ada di Kecamatan Teluk Jambe Timur, Lalu permasalahan yang kedua adalah mengenai jaringan alokasi distribusi susu tersebut adapun Metode Penyelesaian dari permasalahan tersebut adalah dengan menggunakan metode Penugasan (Assignment/Hungarian) dan metode Networking.

\section{Program Linear}

Program linear bertujuan untuk mendapatkan alternatif penggunaan terbaik atas sumber-sumber organisasi. Kata sifat linear digunakan untuk menunjukkan fungsi matematik digunakan pada bentuk linear dalam arti hubungan langsung dan persis proporsional program menyatakan penggunaan teknik matematika tertentu [8]. Model matematis pada pemrograman linear adalah sebagai berikut [1]:

Fungsi tujuan:

Maksimumkan/minimumkan

$z=\sum C_{j} \cdot x_{j}$

Dimana:

$x_{j}$ : Variabel Keputusan ke-j

$c_{j}$ : Parameter Fungsi Tujuan Ke-j

$b_{i}$ : Kapasitas Kendala ke-i

$a_{i j}$ : Parameter fungsi kendala ke-I untuk variable keputusan ke-j

$i: 1,2, \ldots \mathrm{m}$

$j: 1,2, \ldots . \mathrm{m}$

Terhadap fungsi kendala:

$a_{11} x_{1}+a_{12} x_{2}+\cdots+a_{1 n} x_{n} \geq$ atau $\leq b_{1}$ 


$$
\begin{aligned}
& a_{21} x_{1}+a_{22} x_{2}+\cdots+a_{2 n} x_{n} \geq \text { atau } \leq b_{2} \\
& \cdots \cdots+\cdots . .+\cdots+\cdots+\text { atau } \leq \cdots \\
& a_{m 1} x_{1}+a_{m 2} x_{2}+\cdots+a_{m n} x_{n} \geq \text { atau } \leq b_{m}
\end{aligned}
$$

\section{Metode Hungarian}

Metode Hungarian merupakan jumlah sumber-sumber yang ditugaskan harus sesuai atau sama dengan jumlah tujuan yang akan diselesaikan, masing-masing sumber ditugaskan hanya untuk satu tujuan. Jadi, masalah penugasan akan mencakup sejumlah $\mathrm{n}$ sumber yang mempunyai $\mathrm{n}$ tujuan [2]. Pada metode Hungarian harus adanya penyesuaian antara supply dan demand [4]. Bentuk umum model matematis penugasan adalah sebagai berikut:

$T=\sum_{i=1}^{n} \sum_{j=1}^{n} T_{i j} X_{i j}$

Dengan:[2]

$\mathrm{T}=$ total waktu pengantaran barang

$\mathrm{T}_{\mathrm{ij}} \quad=$ waktu yang diperlukan untuk karyawan

$X_{i j} \quad=$ satuan barang yang akan di cari

Adapun Langkah-langkah penggunaan metode Hungarian adalah sebagai berikut [9]:

1. Tentukan elemen terbesar (karena kasus maksimasi) dari setiap baris yang ada di soal

2. Elemen baris terbesar dikurangi dengan semua elemen dari barisnya.

3. Pilih nilai terkecil dari setiap kolom, setiap elemen dikurangkan dengan nilai terkecil dari setiap kolom tersebut.

4. Coret (tutup) baris dan kolom yang memiliki nilai nol, dimulai dari baris atau kolom yang memiliki nol yang paling banyak

5. Angka yang terbuka dikurangi nilai elemen terkecil yang terbuka, dan angka intersection ditambah nilai elemen terkecil yang terbuka.

6. Karena belum optimal karena jumlah garis belum sama dengan jumlah kolom dan baris maka harus dilakukan perhitungan ulang sama seperti langkah-langkah diatas, hingga jumlah garis yang didapat sama dengan jumlah kolom dan baris yang dimiliki oleh tabelnya.

7. Hasil setelah melewati beberapa iterasi maka solusi optimal

\section{Analisis jaringan (Networking)}

Jaringan merupakan suatu himpunan titik yang disebut simpul (node), dan suatu himpunan kurva, yang disebut cabang (busur), yang dapat menghubungkan titik simpul tertentu, Networking sendiri dibagi menjadi tiga yaitu, Model Shortest Route (persoalan rute terpendek), Model Minimal Spanning Tree (persoalan rentang pohon minimum), Model Maximum-flow (persoalan aliran maksimum) [10].

\section{Model Minimal Spanning Tree (Persoalan Rentang Pohon Minimum)}

Spanning Tree pada suatu graph adalah subgraph minimal yang menghubungkan semua simpul pada graph. Apabila graph tersebut adalah graph berbobot (Weighted Graph), kemudian dari pohon rentang yang dimiliki oleh graph diartikan sebagai penjumlahan dari bobot seluruh cabang pada pohon rentang maka diperoleh pohon rentang yang memiliki bobot. Pohon rentang yang memiliki bobot terkecil pada suatu graph disebut Pohon rentang Minimum (Minimum spanning tree) [11]. Penyelesaian masalah dengan menggunakan spanning tree mempertimbangkan beberapa faktor, seperti biaya, jarak, waktu serta tenaga kerja yang dibutuhkan [12]. Penggunaan metode spanning tree merupakan salah satu pemodelan graf yang digunakan dalam mencari nilai minimum dari jalur suatu graf. [13], graf terdiri dari dua bagian yaitu himpunan titik dan himpunan garis [14]. Sisi-sisi di dalam graf terlebih dahulu diurutkan berdasarkan bobotnya dari yang terkecil ke yang terbesar [15].

\section{Hasil dan Pembahasan}

\section{Permasalahan Penugasan (Metode Assignment)}

Depot Susu Nasional Kecamatan Teluk Jambe Timur ini, memiliki 9 karyawan yang bertugas menjajakan produk susu di sekitar wilayah Kecamatan Teluk Jambe Timur, dengan jam kerja dimulai pukul 09.00-18.00 WIB, dimana karyawan bertugas mendistribusikan susu nasional ke desa-desa yang ada di Kecamatan Teluk Jambe Timur Karawang. Setiap karyawan harus memiliki alokasi wilayah distribusinya 
sendiri, di bawah ini ada data penugasan karyawan Depot Susu Nasional Kecamatan Teluk Jambe Timur Karawang ditunjukkan pada Tabel 1.

Tabel 1. Penugasan karyawan Depot Susu Nasional Teluk Jambe Timur

\begin{tabular}{lccccccccc}
\hline \multirow{2}{*}{ Tujuan } & \multicolumn{10}{c}{ Karyawan } \\
\cline { 2 - 9 } & Eman & Oyeh & Acim & Tarmu & Danu & Datuk & Yanto & Dullah & Sukrim \\
\hline Sukamakmur & 110 & 121 & 76 & 197 & 126 & 150 & 51 & 98 & 76 \\
Pinalayungan & 150 & 200 & 85 & 251 & 140 & 165 & 55 & 140 & 106 \\
Puseurjaya & 120 & 150 & 80 & 200 & 150 & 160 & 60 & 120 & 120 \\
Sinarbaya & 140 & 185 & 100 & 140 & 145 & 150 & 55 & 130 & 100 \\
Sukaharja & 120 & 160 & 90 & 230 & 165 & 190 & 60 & 120 & 110 \\
Sukalayu & 150 & 130 & 110 & 185 & 135 & 168 & 55 & 179 & 110 \\
Teluk Jambe & 135 & 85 & 84 & 250 & 122 & 160 & 50 & 145 & 120 \\
Wadas & 61 & 75 & 50 & 97 & 106 & 92 & 50 & 85 & 80 \\
Purwadana & 100 & 115 & 80 & 165 & 135 & 140 & 55 & 120 & 115 \\
\hline
\end{tabular}

Sumber: Depot Susu Nasional Teluk Jambe Timur

Jumlah alokasi produk susu yang terjual oleh masing-masing karyawan, dalam pendistribusian produk sebelum memakai metode Hungarian dapat dilihat pada Tabel 2.

Tabel 2. Hasil perhitungan penjualan produk sebelum memakai metode Hungarian

\begin{tabular}{lcc}
\hline \multicolumn{1}{c}{ Tujuan } & Karyawan & Penjualan \\
\hline Sukamakmur & Yanto & 51 \\
Pinalayungan & Acim & 85 \\
Puseurjaya & Eman & 120 \\
Sinarbaya & Dullah & 130 \\
Sukaharja & Danu & 135 \\
Sukalayu & Sukrim & 110 \\
Teluk Jambe & Oyeh & 85 \\
Wadas & Tarmu & 97 \\
Purwadana & Datuk & 140 \\
\hline & & 953 \\
\hline
\end{tabular}

Sumber: Depot Susu Nasional Teluk Jambe Timur

Pada Tabel 2 di atas jumlah alokasi produk susu yang terjual oleh masing-masing karyawan, dalam pendistribusian produk sebelum memakai metode Hungarian didapat bahwa penjualan produk susu dengan total penjualan sebanyak 953. Adapun hasil pendistribusian produk susu Nasional dengan menggunakan metode Hungarian adalah sebagai berikut:

1. Tentukan elemen terbesar (karena kasus maksimasi) dari setiap baris yang ada pada soal seperti tertera pada Tabel 3.

Tabel 3. Nilai elemen (penjualan terbesar) setiap baris

\begin{tabular}{lccccccccc}
\hline \multirow{2}{*}{ Tujuan } & \multicolumn{10}{c}{ Karyawan } \\
\cline { 2 - 10 } & Eman & Oyeh & Acim & Tarmu & Danu & Datuk & Yanto & Dullah & Sukrim \\
\hline Sukamakmur & 110 & 121 & 76 & 197 & 126 & 150 & 51 & 98 & 76 \\
Pinalayungan & 150 & 200 & 85 & 251 & 140 & 165 & 55 & 140 & 106 \\
Puseurjaya & 120 & 150 & 80 & 200 & 150 & 160 & 60 & 120 & 120 \\
Sinarbaya & 140 & 185 & 100 & 140 & 145 & 150 & 55 & 130 & 100 \\
Sukaharja & 120 & 160 & 90 & 230 & 165 & 190 & 60 & 120 & 110 \\
Sukalayu & 150 & 130 & 110 & 185 & 135 & 168 & 55 & 179 & 110 \\
Teluk Jambe & 135 & 85 & 84 & 250 & 122 & 160 & 50 & 145 & 120 \\
Wadas & 61 & 75 & 50 & 97 & 106 & 92 & 50 & 85 & 80 \\
Purwadana & 100 & 115 & 80 & 165 & 135 & 140 & 55 & 120 & 115 \\
\hline
\end{tabular}

Sumber: Perhitungan penelitian 
2. Elemen baris terbesar dikurangi dengan semua elemen dari barisnya.

Tabel 4. Pengurangan elemen baris terbesar terhadap barisnya

\begin{tabular}{lccccccccc}
\hline \multirow{2}{*}{ Tujuan } & \multicolumn{10}{c}{ Pekerja } \\
\cline { 2 - 9 } & Eman & Uyeh & Acim & Tarmu & Danu & Datuk & Yanto & Dulah & Sukrim \\
\hline Sukamakmur & 69 & 58 & 103 & 0 & 53 & 29 & 128 & 81 & 103 \\
Pinalayungan & 101 & 51 & 166 & 0 & 111 & 86 & 196 & 111 & 145 \\
Puserjaya & 80 & 50 & 120 & 0 & 50 & 40 & 140 & 80 & 80 \\
Sinarbaya & 100 & 55 & 140 & 0 & 95 & 90 & 185 & 110 & 140 \\
Sukaharja & 110 & 70 & 140 & 0 & 65 & 40 & 170 & 110 & 120 \\
Sukalayu & 35 & 55 & 75 & 0 & 50 & 17 & 130 & 6 & 75 \\
Teluk Jambe & 115 & 165 & 166 & 0 & 128 & 90 & 200 & 105 & 130 \\
Wadas & 45 & 31 & 56 & 9 & 0 & 14 & 56 & 21 & 26 \\
Purwadana & 65 & 50 & 86 & 0 & 30 & 25 & 110 & 45 & 50 \\
\hline
\end{tabular}

Sumber: Perhitungan penelitian

3. Pilih nilai terkecil dari setiap kolom, setiap elemen dikurangkan dengan nilai terkecil dari setiap kolom tersebut.

Tabel 5. Nilai terkecil dalam setiap kolom

\begin{tabular}{|c|c|c|c|c|c|c|c|c|c|}
\hline \multirow{2}{*}{ Tujuan } & \multicolumn{9}{|c|}{ Pekerja } \\
\hline & Eman & Uyeh & Acim & Tarmu & Danu & Datuk & Yanto & Dulah & Sukrim \\
\hline Sukamakmur & 69 & 58 & 103 & 0 & 53 & 29 & 128 & 81 & 103 \\
\hline Pinalayungan & 101 & 51 & 166 & 0 & 111 & 86 & 196 & 111 & 145 \\
\hline Puserjaya & 80 & 50 & 120 & 0 & 50 & 40 & 140 & 80 & 80 \\
\hline Sinarbaya & 100 & 55 & 140 & 0 & 95 & 90 & 185 & 110 & 140 \\
\hline Sukaharja & 110 & 70 & 140 & 0 & 65 & 40 & 170 & 110 & 120 \\
\hline Sukalayu & 35 & 55 & 75 & 0 & 50 & 17 & 130 & 6 & 75 \\
\hline Teluk Jambe & 115 & 165 & 166 & 0 & 128 & 90 & 200 & 105 & 130 \\
\hline Wadas & 45 & 31 & 56 & 9 & 0 & 14 & 56 & 21 & 26 \\
\hline Purwadana & 65 & 50 & 86 & 0 & 30 & 25 & 110 & 45 & 50 \\
\hline
\end{tabular}

Tabel 6. Hasil pengurangan setiap elemen kolom dengan nilai terkecil dalam kolom

\begin{tabular}{lccccccccc}
\hline \multirow{2}{*}{ Tujuan } & \multicolumn{10}{c}{ Pekerja } \\
\cline { 2 - 10 } & Eman & Uyeh & Acim & Tarmu & Danu & Datuk & Yanto & Dulah & Sukrim \\
\hline Sukamakmur & 34 & 27 & 47 & 0 & 23 & 15 & 72 & 75 & 77 \\
Pinalayungan & 66 & 20 & 110 & 0 & 81 & 72 & 140 & 105 & 119 \\
Puserjaya & 45 & 19 & 64 & 0 & 20 & 26 & 84 & 74 & 54 \\
Sinarbaya & 65 & 24 & 84 & 0 & 65 & 76 & 129 & 104 & 114 \\
Sukaharja & 75 & 39 & 84 & 0 & 35 & 26 & 114 & 104 & 64 \\
Sukalayu & 0 & 24 & 18 & 0 & 20 & 3 & 74 & 0 & 49 \\
Teluk Jambe & 80 & 134 & 110 & 0 & 98 & 76 & 144 & 99 & 104 \\
Wadas & 10 & 0 & 0 & 9 & 0 & 0 & 0 & 15 & 0 \\
Purwadana & 30 & 19 & 29 & 0 & 0 & 11 & 54 & 39 & 24 \\
\hline
\end{tabular}

Sumber: Perhitungan penelitian

4. Coret (tutup) baris dan kolom yang memiliki nilai nol, dimulai dari baris atau kolom yang memiliki nol yang paling banyak

Tabel 7. Pencoretan nilai nol

\begin{tabular}{lccccccccc}
\hline \multirow{2}{*}{ Tujuan } & \multicolumn{10}{c}{ Pekerja } \\
\cline { 2 - 11 } & Eman & Uyeh & Acim & Tarmu & Danu & Datuk & Yanto & Dulah & Sukrim \\
\hline Sukamakmur & 34 & 27 & 47 & 0 & 23 & 15 & 72 & 75 & 77 \\
Pinalayungan & 66 & 20 & 110 & 0 & 81 & 72 & 140 & 105 & 119 \\
Puserjaya & 45 & 19 & 64 & 0 & 20 & 26 & 84 & 74 & 54 \\
Sinarbaya & 65 & 24 & 84 & 0 & 65 & 76 & 129 & 104 & 114 \\
Sukaharja & 75 & 39 & 84 & 0 & 35 & 26 & 114 & 104 & 64 \\
Sukalayu & 0 & 24 & 18 & 0 & 20 & 3 & 74 & 0 & 49 \\
\hline
\end{tabular}




\begin{tabular}{lccccccccc}
\hline Teluk Jambe & 80 & 134 & 110 & 0 & 98 & 76 & 144 & 99 & 104 \\
Wadas & 10 & 0 & 0 & 9 & 0 & 0 & 0 & 15 & 0 \\
Purwadana & 30 & 19 & 29 & 0 & 0 & 11 & 54 & 39 & 24 \\
\hline
\end{tabular}

Sumber: Perhitungan penelitian

Karena jumlah garis kurang dari jumlah baris atau kolom, maka dilakukan pencoretan atau penutupan, atau penarikan garis lagi.

5. Angka yang terbuka dikurangi nilai elemen terkecil yang terbuka, dan angka intersection ditambah nilai elemen terkecil yang terbuka.

Tabel 8. Pengurangan elemen terkecil terbuka dan angka intersection

\begin{tabular}{lccccccccc}
\hline \multirow{2}{*}{ Tujuan } & \multicolumn{10}{c}{ Karyawan } \\
\cline { 2 - 9 } & Eman & Oyeh & Acim & Tarmu & Danu & Datuk & Yanto & Dullah & Sukrim \\
\hline Sukamakmur & 19 & 12 & 23 & 0 & 8 & 0 & 57 & 60 & 62 \\
Pinalayungan & 51 & 5 & 95 & 0 & 66 & 57 & 125 & 90 & 104 \\
Puseurjaya & 30 & 4 & 49 & 0 & 5 & 11 & 69 & 59 & 39 \\
Sinarbaya & 50 & 9 & 69 & 0 & 50 & 61 & 114 & 89 & 99 \\
Sukaharja & 60 & 24 & 69 & 0 & 20 & 11 & 99 & 89 & 49 \\
Sukalayu & 0 & 24 & 18 & 15 & 20 & 3 & 74 & 0 & 49 \\
Teluk Jambe & 65 & 119 & 95 & 0 & 83 & 61 & 129 & 84 & 89 \\
Wadas & 10 & 0 & 0 & 24 & 0 & 0 & 0 & 15 & 0 \\
Purwadana & 30 & 19 & 29 & 15 & 0 & 11 & 54 & 39 & 24 \\
\hline
\end{tabular}

Sumber: Perhitungan penelitian

6. Karena belum optimal karena jumlah garis belum sama dengan jumlah kolom dan baris maka harus dilakukan perhitungan ulang sama seperti langkah-langkah diatas, hingga jumlah garis yang didapat sama dengan jumlah kolom dan baris yang dimiliki oleh tabelnya.

7. Hasil setelah melewati beberapa iterasi maka solusi optimalnya akan seperti di bawah ini:

Tabel 9. Solusi optimal

\begin{tabular}{lcccccccccc}
\hline \multirow{2}{*}{ Tujuan } & \multicolumn{10}{c}{ Pekerja } \\
\cline { 2 - 10 } & Eman & Oyeh & Acim & Tarmu & Danu & Datuk & Yanto & Dullah & Sukrim \\
\hline Sukamakmur & 1 & 35 & 0 & 47 & 15 & 16 & 0 & 23 & 35 \\
Pinalayungan & 5 & 0 & 35 & 19 & 45 & 45 & 40 & 25 & 49 \\
Puseurjaya & 0 & 15 & 5 & 35 & 0 & 15 & 0 & 10 & 0 \\
Sinarbaya & 0 & 0 & 5 & 15 & 25 & 45 & 25 & 20 & 40 \\
Sukaharja & 15 & 20 & 10 & 20 & 0 & 0 & 15 & 25 & 25 \\
Sukalayu & 19 & 84 & 24 & 99 & 64 & 56 & 54 & 0 & 59 \\
Teluk Jambe & 0 & 95 & 16 & 0 & 43 & 30 & 25 & 0 & 15 \\
Wadas & 49 & 80 & 25 & 128 & 34 & 73 & 0 & 35 & 30 \\
Purwadana & 15 & 45 & 0 & 65 & 10 & 30 & 0 & 5 & 0 \\
\hline
\end{tabular}

Sumber: Perhitungan penelitian

Hasil tersebut sudah optimal karena setiap karyawan sudah memiliki satu jalur distribusi sendiri, maka hasil optimal dengan pendistribusian produk setiap karyawan dapat dilihat pada Tabel 10.

Tabel 10. Hasil penjualan produk menggunakan metode Hungarian

\begin{tabular}{lcc}
\hline \multicolumn{1}{c}{ Tujuan } & Pekerja & Produk Yang terjual \\
\hline Sukamakmur & Acim & 76 \\
Pinalayungan & Oyeh & 200 \\
Puseurjaya & Danu & 150 \\
Sinarbaya & Eman & 140 \\
Sukaharja & Datuk & 190 \\
Sukalayu & Dulah & 179 \\
Teluk Jambe & Tarmu & 250 \\
Wadas & Yanto & 50 \\
Purwadana & Sukrim & 115 \\
\hline & Total & 1350 \\
\hline
\end{tabular}

Sumber: Perhitungan penelitian 


\section{Permasalahan Jaringan Distribusi (Networking Spanning Tree)}

Adapun data dari permasalahan jaringan distribusi (Networking Spanning Tree) pada depot susu nasional dapat dilihat pada Tabel 11.

Tabel 11. Jaringan titik awal sampai tujuan

\begin{tabular}{lc}
\hline Titk Awal ke Titik Tujuan & Jarak (KM) \\
\hline Teluk Jambe - Pinalayungan & 3,1 \\
Teluk Jambe - Sinarbaya & 4,2 \\
Teluk Jambe - Puseurjaya & 6,19 \\
Pinalayungan - Sinarbaya & 3,29 \\
Pinalayungan - Sukaharja & 4,19 \\
Pinalayungan - Sukalayu & 7,73 \\
Sinarbaya - Puseurjaya & 4,24 \\
Sinarbaya - Sukalayu & 6,74 \\
Sinarbaya - Wadas & 7,82 \\
Puseurjaya - Sukamakmur & 5,42 \\
Sukaharja - Sukalayu & 7,64 \\
Sukalayu - Purwadana & 4,38 \\
Sukaharja - Purwadana & 7,92 \\
Sukamakmur - Wadas & 9,00 \\
Purwadana - Wadas & 10,84 \\
\hline Sura
\end{tabular}

Sumber: Depot Susu Nasional Telukjambe

Penggambaran jalur distribusi dilakukan untuk mempermudah dalam pengolahan data, dan jalur distribusi diatas dapat digambarkan melalui bagan diagram Gambar 1.

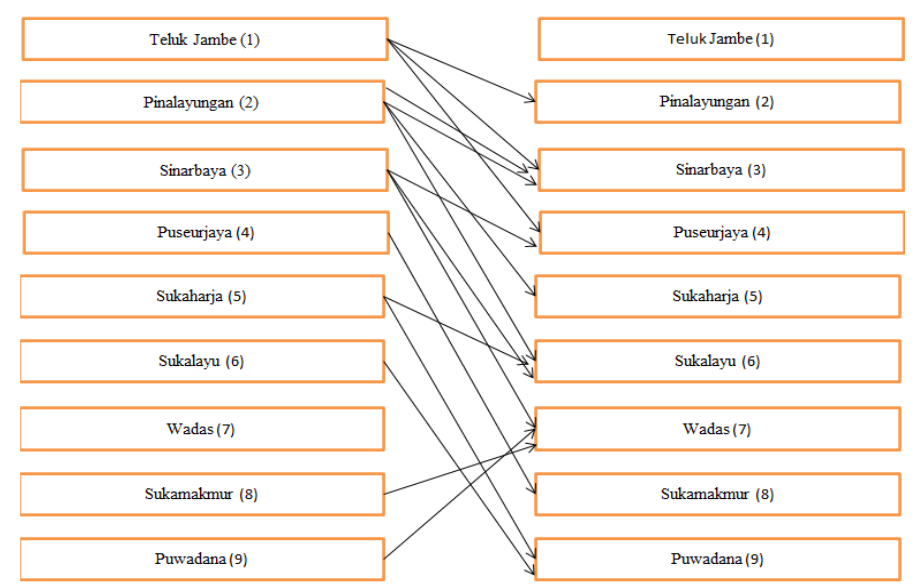

Gambar 1. Bagan Jaringan Pendistribusian Susu Nasional Sumber: Depot Susu Nasional Telukjambe

Tabel 12. Data Sisi dan Jarak

\begin{tabular}{ccc}
\hline Sisi & Titik & Jarak \\
\hline X1 & $(1-2)$ & 3,1 \\
X2 & $(1-3)$ & 4,2 \\
X3 & $(1-4)$ & 6,19 \\
X4 & $(2-3)$ & 3,29 \\
X5 & $(2-5)$ & 4,19 \\
X6 & $(2-6)$ & 7,73 \\
X7 & $(3-4)$ & 4,24 \\
X8 & $(3-6)$ & 6,74 \\
X9 & $(3-7)$ & 7,82 \\
X10 & $(4-8)$ & 5,42 \\
X11 & $(5-6)$ & 7,64 \\
X12 & $(6-9)$ & 4,38 \\
X13 & $(5-9)$ & 7,92 \\
\hline
\end{tabular}




\begin{tabular}{ccc}
\hline X14 & $(8-7)$ & 9,00 \\
X15 & $(9-7)$ & 10,84 \\
\hline rer: Depot Susu Nasional Telukjambe
\end{tabular}

1. Pemecahan Model

Berdasarkan Tabel 12 maka data-data tersebut dapat dikembangkan modelnya ke dalam bentuk gambar grafik jaringan pendistribusian kripiknya, seperti Gambar 2.

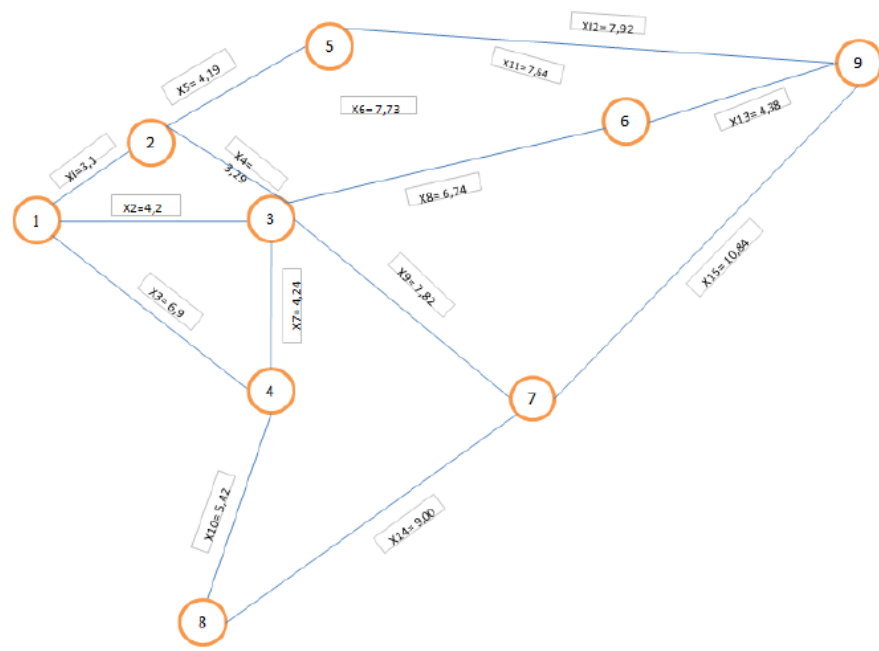

Gambar 2. Grafik jaringan pendistribusian Susu Nasional Sumber: Depot Susu Nasional Teluk Jambe

Untuk menyelesaikan permasalahan maka dilakukanlah pembuatan iterasi untuk menentukan jalur mana yang belum optimal, adapun iterasi-iterasi tersebut adalah sebagai berikut:

\section{Iterasi 1}

Conected Node

Unconected Node

Arch

Jarak A-B (X1)
: A,B

: C,D,E,F,G,H,I,

: A-B

: 3,1 Kilometer.

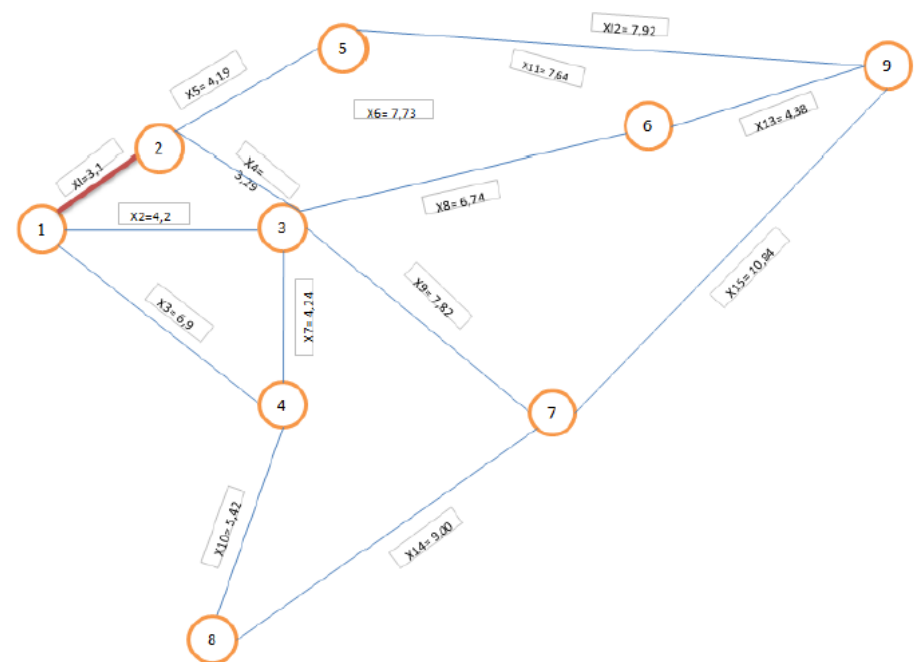

Gambar 3. Iterasi 1 pendistribusian susu nasional Sumber: Hasil perhitungan 
Iterasi 2

Conected Node

: A,B, C

Unconected Node

: D,E,F,G,H,I,

Arch

: A-B, B-C

Jarak B-C (X4)

: 3,29 Kilometer

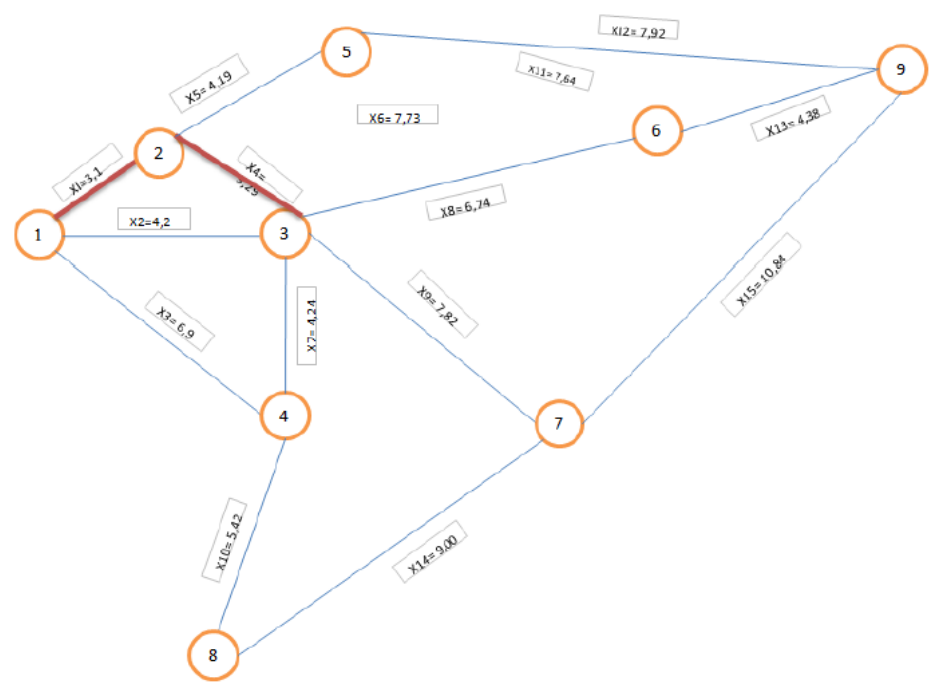

Gambar 4. Iterasi 2 pendistribusian Susu Nasional Sumber: Hasil perhitungan

\section{Iterasi $\mathbf{3}$}

Conected Node Unconected Node Arch

Jarak B-E (X5)

: A,B, C, E

: D, F,G,H,I,

: A-B, B-C, B-E

: 4,19 Kilometer.

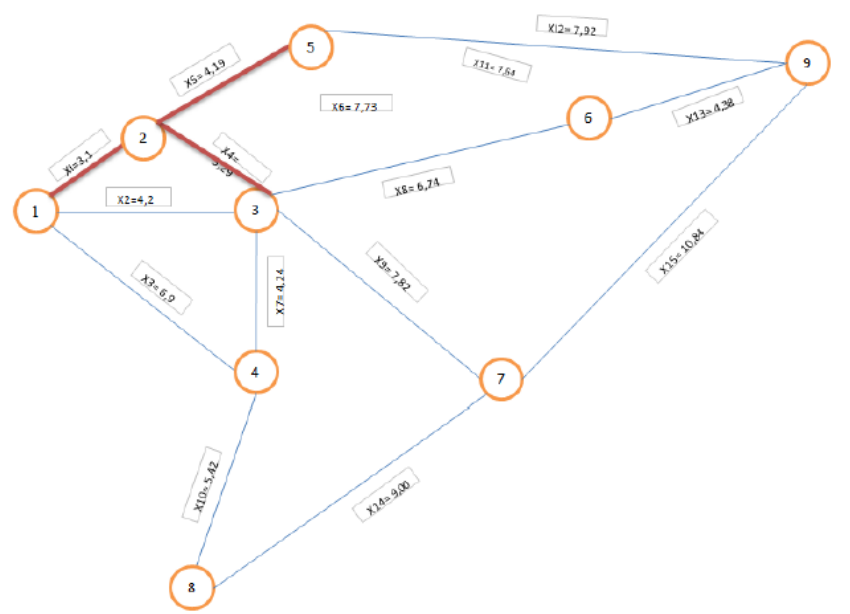

Gambar 5. Iterasi 3 pendistribusian Susu Nasional Sumber: Hasil perhitungan

\section{Iterasi 4}

Conected Node

Unconected Node

Arch

Jarak C-D (X7)
: A,B, C, E, D

: F, G,H,I,

: A-B, B-C, B-E, C-D

: 4,24 Kilometer. 


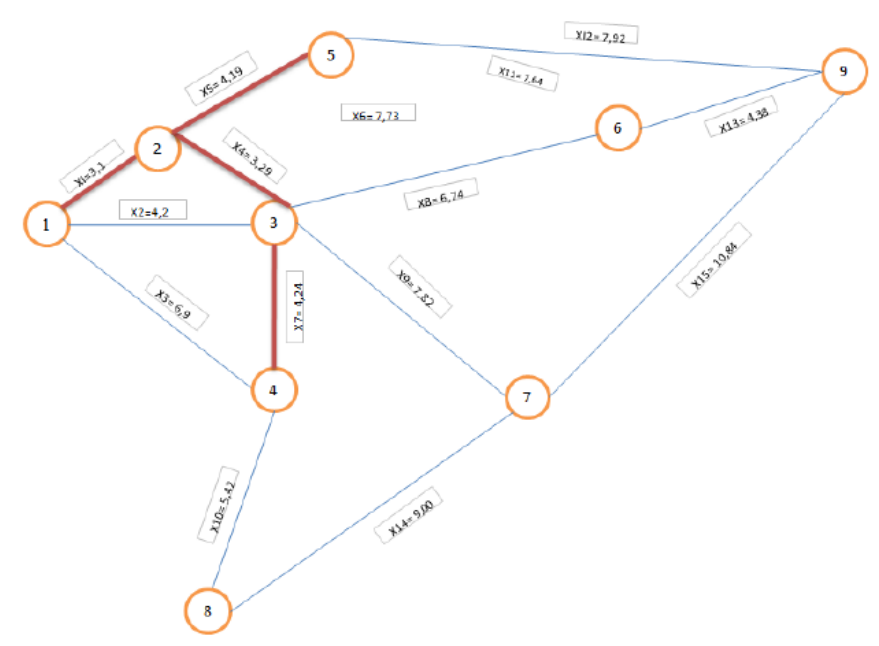

Gambar 6. Iterasi 4 pendistribusian Susu Nasional. Sumber: Hasil perhitungan

\section{Iterasi $\mathbf{5}$}

Conected Node

Unconected Node Arch

Jarak D-H (X10)
: A,B, C, E, D, H

$: F, G, I$,

: A-B, B-C, B-E, C-D, D-H

: 5,42 Kilometer.

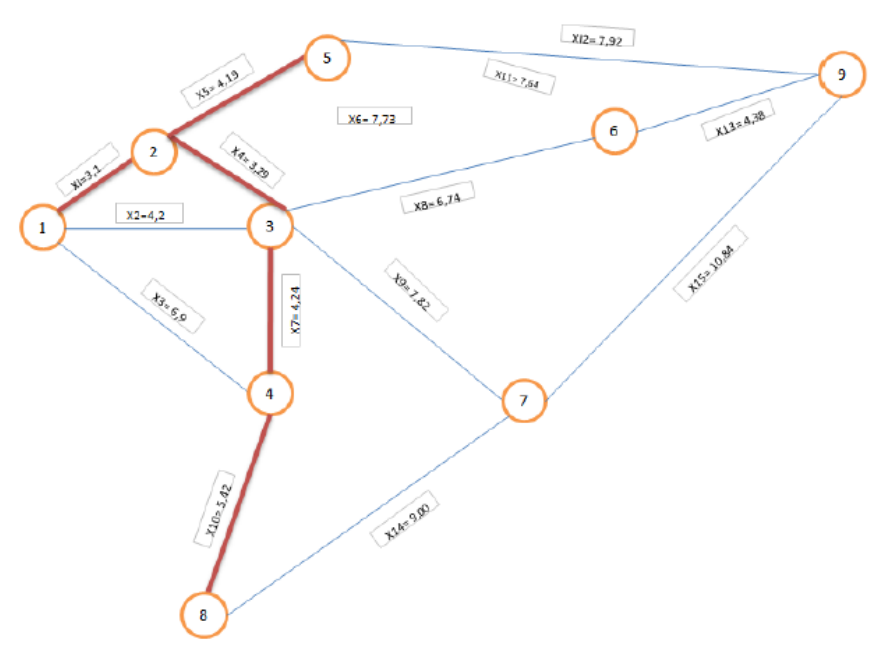

Gambar 7. Iterasi 5 pendistribusian Susu Nasional Sumber: Hasil perhitungan

\section{Iterasi 6}

Conected Node

Unconected Node

Arch

Jarak C-F (X8)

: A,B, C, E, D, H, F

: G, I,

: A-B, B-C, B-E, C-D, D-H, C-F.

: 6,74 Kilometer. 


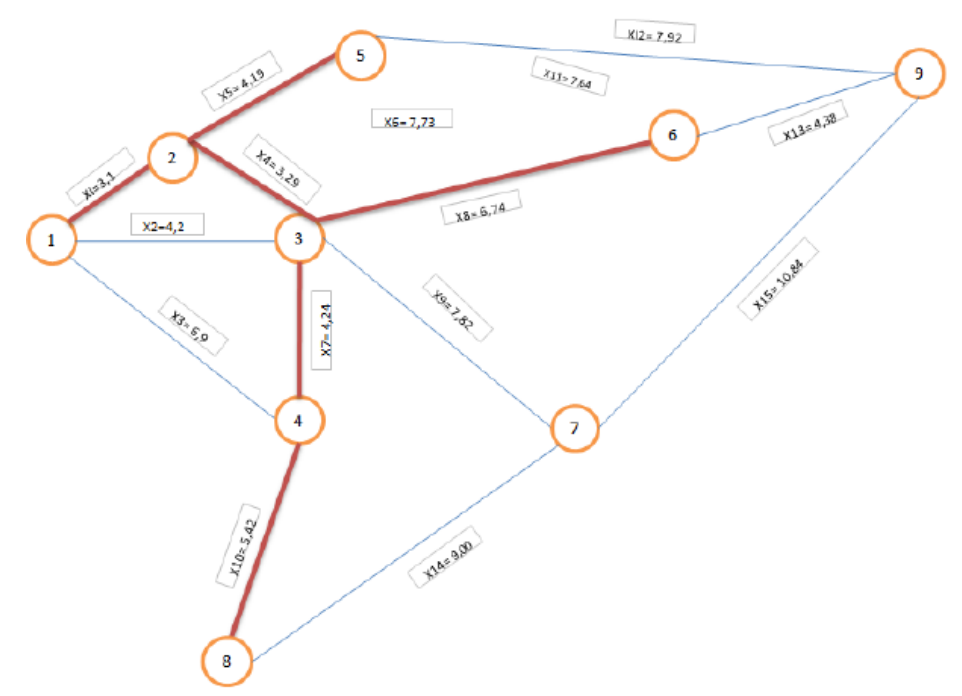

Gambar 8. Iterasi 6 pendistribusian Susu Nasional Sumber: Hasil perhitungan

\section{Iterasi 7}

Conected Node

Unconected Node Arch

Jarak F-I (X13)
: A,B, C, E, D, H, F, I

$: \mathrm{G}$,

: A-B, B-C, B-E, C-D, D-H, C-F, F-I

: 4,38 Kilometer.

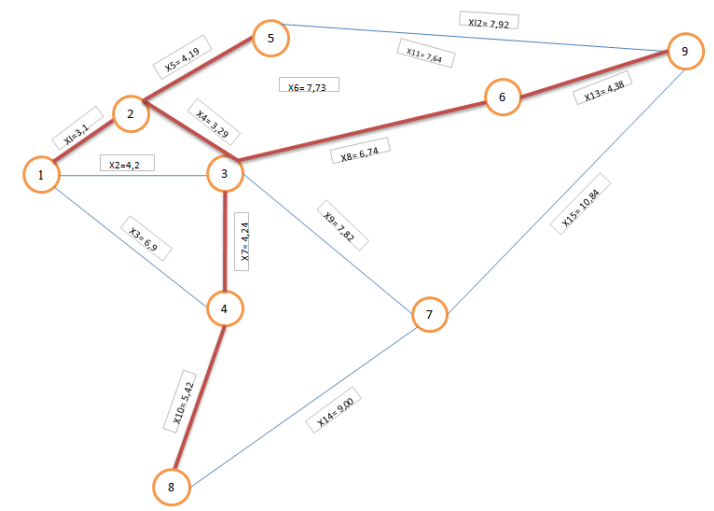

Gambar 9. Iterasi 7 pendistribusian Susu Nasional Sumber: Hasil perhitungan

\section{Iterasi 8}

Conected Node

Unconected Node

Arch

Jarak C-G (X9)
: A,B, C, E, D, H, F, I, G

: - (Tidak ada simpul yang tidak terhubung)

: A-B, B-C, B-E, C-D, D-H, C-F, F-I, C-G

: 7,82 Kilometer. 


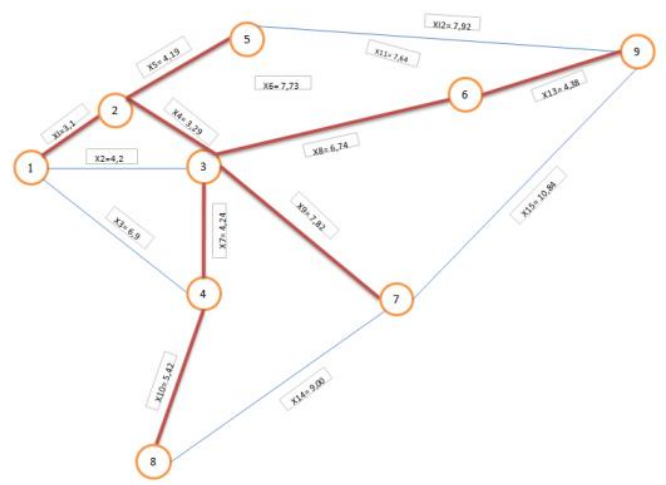

Gambar 11. Iterasi 8 pendistribusian Susu Nasional Sumber: Hasil perhitungan

Karena semua jalur distribusi sudah terhubung dalam jaringan, maka iterasi dikatakan sudah selesai dan optimal dengan jarak yang paling optimal, seperti Gambar 12.

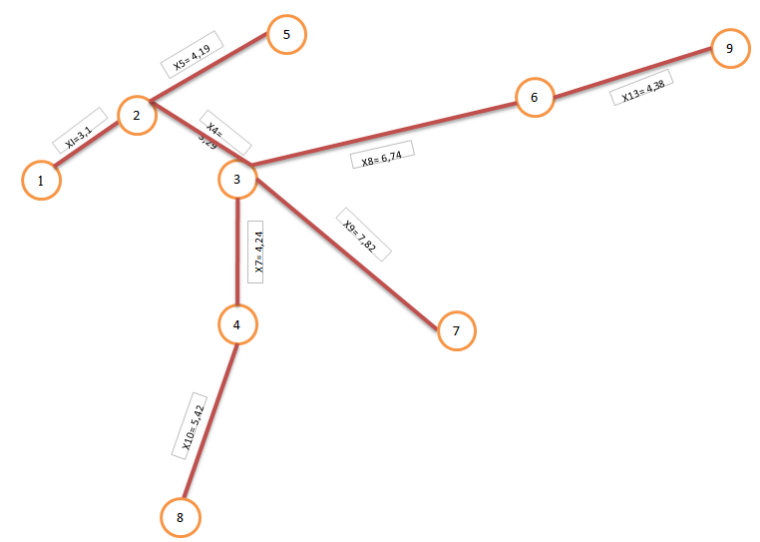

Gambar 12. Minimum Spanning Tree jaringan Pendistribusian Depot Susu Nasional Sumber: Hasil perhitungan

Maka Fungsi Tujuan $\mathrm{Z}$ menjadi:

$$
\begin{aligned}
& Z=X 1+X 4+X 5+X 7+X 10+X 8+X 13+X 9 \\
& Z=(A-B)+(B-C)+(B-F)+(C-D)+(D-H)+(C-F)+(F-I)+(C-G) \\
& Z=3,1+3,29+4,19+4,24+5,42+6,74+4,38+7,82=39,18 \mathrm{~km}
\end{aligned}
$$

\section{Kesimpulan}

Penyelesaian (solusi) dari permasalahan penugasan dapat disimpulkan alokasi totalnya berjumlah 1350 buah susu nasional, dengan wilayah Sukamakmur yang bertugas mendistribusikan adalah pekerja bernama Acim dengan jumlah produk yang terjual adalah sebesar 76 buah susu nasional. Untuk wilayah Pinalayungan yang bertugas Oyeh dengan jumlah produk yang terjual 200 buah susu, wilayah Puseurjaya yang bertugas Danu dengan jumlah produk yang terjual 150 buah susu. Wilayah Sinarbaya yang bertugas Eman dengan jumlah produk yang terjual 140 buah susu, Sukaharja yang bertugas Datuk jumlah produk yang terjual 190 buah susu. Untuk wilayah Sukalayu yang bertugas mendistribusikan adalah pekerja bernama Dullah dengan jumlah produk yang terjual adalah sebesar 179 buah susu nasional, Teluk Jambe yang bertugas Tarmu dengan jumlah produk yang terjual 250 buah susu. Wilayah Wadas yang bertugas Yanto dengan jumlah produk yang terjual adalah sebesar 50 buah susu nasional dan untuk wilayah Purwadana yang bertugas mendistribusikan adalah pekerja bernama Sukrim dengan jumlah produk yang terjual adalah sebesar 115 buah susu nasional.

Untuk mengetahui solusi minimum mengenai jarak yang harus ditempuh dalam setiap distribusi susu nasional di wilayah Kecamatan Teluk Jambe Timur, adalah dengan menggunakan metode Networking Spanning Tree dengan kasus minimalisir jarak, sehingga diharapkan produktivitas penjualan meningkat, dan keuntungan juga akan meningkat, dengan besarnya jarak minimum yang harus ditempuh oleh pekerja 
dalam mendistribusikan susu nasional pada Kecamatan Teluk Jambe Timur Karawang adalah sebesar 39,18 $\mathrm{Km}$.

\section{Ucapan Terimakasih}

Kami mengucapkan terima kasih kepada Tuhan yang Maha Esa, berkat-Nya kami dapat menyelesaikan penelitian dengan berjalan lancar, serta kepada Universitas Singaperbangsa Karawang serta kepada rekan-rekan yang telah membantu dalam penelitian ini.

\section{Referensi}

[1] N. H. N. Wirum, "Optimasi pembagian tugas karyawan dengan metode Hungarian," 2017.

[2] E. Rahmawati, N. Satyahadewi, F. Intisari, K. Kunci, M. Biaya, and H. Kuhn, "Optimalisasi Masalah Penugasan Menggunakan Metode Hungarian (Studi kasus pada PT Pos Indonesia (Persero) Pontianak)," Bul. Ilm. Mat. Stat. danTerapannya, vol. 04, no. 3, pp. 363-370, 2015.

[3] W. O. Widyarto and D. Triana, "Penugasan Operator Mesin Produksi dengan Menggunakan Metode Hungarian dan Algoritma Generate and Test," J. Intech Tek. Ind., vol. 1, no. 1, pp. 1-9, 2015.

[4] N. Husniati, J. A. Judiarni, and Doddy Adhimursandi, "Analisis Assigment Problem Berdasarkan Penilaian Kinerja karyawan Menggunakan Metode Hungarian ( Hungarian Method ) dan pohon keputusan (Decision Tree) Assigment analysis based on employee performance appraisal using hungarian method ( Hungarian Method," J. Manaj., vol. 9, no. 1, p. 2, 2017, [Online]. Available: http://journal.feb.unmul.ac.id/index.php/JURNALMANAJEMEN/article/view/2432.

[5] Nelfiyanti and D. Dermawan, "PENENTUAN RUTE DISTRIBUSI BBM YANG OPTIMAL MENGGUNAKAN METODE MINIMAL SPANNING TREE ( MST ),” vol. 1, no. 1, pp. 58-69, 2012.

[6] Nelfiyanti, "OPTIMASI RUTE PENGAMBILAN BARANG TITIPAN UNTUK MEMINIMASI JARAK TEMPUH," J. Tek. Ind. - Univ. Bung Hatta, vol. 1, no. 2, pp. 217-225, 2012.

[7] Rahmawati, Anita, and Mulyono, "MINIMUM SPANNING TREE PADA JARINGAN PENDISTRIBUSIAN," UNNES J. Math., vol. 4, no. 2, 2015.

[8] T. Sriwidadi and E. Agustina, "DENGAN LINEAR PROGRAMMING MELALUI METODE SIMPLEKS Teguh Sriwidadi ; Erni Agustina," Binus Bus. Rev., vol. 4, no. 9, pp. 725-741, 2013.

[9] M. Paendong and J. D. Prang, "Optimisasi Pembagian Tugas Karyawan Menggunakan Metode Hungarian,” J. Ilm. Sains, vol. 11, no. 1, p. 109, 2011, doi: 10.35799/jis.11.1.2011.52.

[10] F. Navyanti and R. Adriyani, "Higiene sanitasi, kualitas fisik dan bakteriologi susu sapi segar perusahaan susu x di surabaya," J. Kesehat. Lingkung., vol. 8, no. 1, pp. 36-47, 2015.

[11] E. W. J. Irwan Afrianto, "PENYELESAIAN MASALAH MINIMUM SPANNING TREE (MST) MENGGUNAKAN ANT COLONY SYSTEM (ACS)," Komputa J. Ilm. Komput. dan Inform., vol. 1, no. 2, pp. 35-40, 2012, doi: 10.34010/komputa.v1i2.59.

[12] Wamiliana, D. Kurniawan, and C. S. N.F., "Perbandingan Kompleksitas Algoritma Prim , Algoritma Kruskal, Dan Algoritma Sollin Untuk Menyelesaikan Masalah Minimum Spanning Tree," vol. 2, no. 1, pp. 60-67, 2014.

[13] Hadiyanto and M. Alhan, "PENENTUAN POHON RENTANG MINIMUM," Telematika, vol. 9, no. 1, pp. 19-30, 2012.

[14] M. Abrori and N. Ubaidillah, "Pengujian Optimalisasi Jaringan Kabel Fiber Optic di Universitas Islam Indonesia Menggunakan Minimum Spanning Tree," vol. 3, no. 1, pp. 49-58, 2014.

[15] D. K. Dwiyanto and S. Nurhayati, "IMPLEMENTASI ALGORITMA KRUSKAL UNTUK DISTRIBUSI LISTRIK (STUDI KASUS PT. PLN CABANG UPJ. JATIBARANG)," UNIKOM Repos., 2014. 